\title{
米 \\ CASAMENTO HOMOSSEXUAL: LEGALIZAÇÃO E RITUAL
}

- RAQUEL LAGE TUMA'

- CARLOS EDUARDO SANTOS MAIA 2

Resuma: Pretende-se neste trabalho apresentar uma síntese de coma fai a institucionalização do matrimônia, bem como o processa da legalização da casamento entre homassexuais, na Brasil e munda e, ainda, alguns movimentas em oposiçãa a esta reivindicação. Também se tem como objetivo analisar como os casamentas homassexuais respaldam-se nos casamentos heterossexuais no que tange an ritual. Camo pracedimento metodalógica utiliza-se de estuda exploratório por meio da pesquisa bibliográfica e documental concernente aos temas de ritual e tradiçãa, institucionalização da casamenta e, especificamente da legislaçãa relacionada à união estável.

Palavras-chaves: Casamenta Homossexual, Legalização Uniãa Civil, Ritual, Tradição.

\section{Introdução}

O casamento possui influência de fatores econômicos, políticos, religiosos e psicossociais, podendo expressar, entre outros aspectos, estratégia de união entre reinados para garantir a posse das terras e os títulos da nobreza; maneira em que duas pessoas sozinhas podem potencializar o status financeiro enquanto casados; modo de oficializar relação romântica, coabitação e manutenção de atividade sexual e reprodutiva, entre outros.
A cerimônia de casamento é a representação da união entre pessoas mediante ato civil, religioso e/ ou familiar. O casamento homossexual, ou casamento igualitário, tem sido difundido e legalizado em alguns estados democráticos. A Holanda foi o primeiro país a reconhecer este direito aos casais homossexuais, aprovando a lei que entrou em vigor em abril de 2001 (PATROCÍNIO, 2013).

A partir daí, lentamente, foram aprovadas leis em outros países que garantem este mesmo direito. Atualmente, 
são mais de vinte, em sua maioria europeus, que possibilitam a união civil entre pessoas do mesmo sexo, tais como: Bélgica, Espanha, Canadá, África do Sul, Noruega, Suécia, Portugal, Islândia, Argentina, Uruguai, Nova Zelândia, França, Brasil, alguns estados dos Estados Unidos, entre outros. A partir desta conquista legal, o casal homossexual que deseja registrar uma cerimônia deste momento especial pode concretizá-lo e, paralelamente, ter os mesmos direitos civis que o casamento garante aos heterossexuais (pensão, herança, adoção, etc.).

Neste artigo, busca-se apresentar de modo exploratório uma comparação entre a realidade brasileira e a de outros países através de pesquisa bibliográfica e documental, considerando-se informações da internet e de revistas sobre a legalização e os rituais de casamentos homossexuais. Nas quinze leis analisadas sobre matrimônio no Brasil, extraíram-se os principais artigos e suas alterações sobre a institucionalização do casamento. As fotografias e reportagens de celebração de casamentos homossexuais nos permitem inferir certa semelhança ritualística com os casamentos heterossexuais (o brinde, as "entradas" de cada pessoa e o posicionamento das personagens durante a cerimônia), bem como a reprodução de suas tradições cerimoniais (uso de vestimentas tradicionais como vestido branco ou terno e recorrência dos símbolos da aliança e do bolo, por exemplo).

\section{Geohistória da Institucionalização e das Leis Matrimoniais no Brasil}

A vida em casal é um padrão normativo. É uma espécie de norma seguida em cânones culturais universais, ou seja, não se conhece sociedade em que não haja a união mediante casamento. Portanto, far-se-á necessário antes de adentrar no objeto deste artigo, apresentar primeiramente como o casamento se torna um ato civil legislado pelo Estado, no caso específico do Brasil, considerando-se as particularidades geohistóricas de sua institucionalização.

No Brasil, o início da oficialização dos casamentos é embasado no Concílio de Trento. Desse modo, durante todo o período que se estende da Colônia até parte do Segundo Império o casamento era um ato eminentemente controlado pela Igreja, dado o regime de padroado ${ }^{3}$. Nos tempos de Colônia, os magistrados de Portugal partiam ao Brasil com a finalidade de ocuparem os postos no poder judiciário, unindo-se à elite local, mas a intenção deste acordo era a troca de 
favores, para representar interesses do país deles, e não local ou do povo (CRISTIANI, 2006). Os magistrados seguiam para o Brasil levando suas famílias, "com o intuito de obter um status social elevado", mas geralmente não faziam parte da nobreza e tinham o objetivo de se igualarem a ela e, para isso, precisavam de benefícios e símbolos materiais (CRISTIANI, 2006, p. 303). Um meio de se alcançarem tais objetivos foi através dos casamentos entre magistrados e filhas de fazendeiros nobres, mediante os quais seriam congregados permanentemente à nobreza. (CRISTIANI, 2006).

A organização do registro civil dos casamentos é instituída a partir da Lei 1.829 , de 9 de setembro de 1870 , quando Dom Pedro II ordenou proceder o recenseamento da população. O Imperador criou uma Diretoria Geral de Estatística, tendo como algumas de suas finalidades organizar os quadros anuais de casamentos, bem como coordenar e apurar os dados estatísticos recolhidos pelas repartições públicas (BRASIL, 1870).

Em 1874, o Ministro e Secretário de Estado dos Negócios do Império, Dr. João Alfredo Corrêa de Oliveira assinou um Decreto Imperial $\mathrm{n}^{\mathrm{o}}$ 5.604 que regulamentou o registro civil dos nascimentos, casamentos e óbitos.
(BRASIL, 1874). Naquela época, ainda não havia a separação entre Igreja e Estado, como pode ser percebido no Capítulo II, artigo 63, que passou algumas instruções sobre o que deveria conter no assento de casamento: a igreja ou capela onde o casamento foi celebrado; o nome do padre ou do eclesiástico que assistiu à celebração e uma declaração de impedimento canônico. Entretanto, no artigo 65 excluiu tais declarações, as quais se referem às cerimônias e formalidades da Igreja Católica, aos acatólicos.

Posteriormente, o Decreto $n^{\circ}$ 9.886, de 7 de março de 1888 trouxe algumas alterações sobre este regulamento do registro civil estabelecido em 1874. As principais modificações foram referentes aos escravos, como exemplo, no Título II, Capítulo II Do registro do casamento, artigo 70, retirou-se o que constava anteriormente do artigo 63 do decreto de 1874: “ $6^{\circ}$ A condição dos conjuges: se ingenuos, libertos, ou escravos, e neste caso o nome do senhor, e a declaração do seu consentimento" (BRASIL, 1874).

Aos 7 de janeiro de 1890, pelo Decreto $n^{\circ}$ 119-A, Marechal Deodoro da Fonseca proibiu a intervenção da autoridade federal e dos Estados federados em matéria religiosa, consagrando plena liberdade de cultos e extinguiu o padroado 
(BRASIL, 1890a), o que fez a separação efetiva da Igreja e o Estado passou a ser laico, instrução ratificada pela primeira constituição republicana de 1891.

Alguns dias depois, aos 24 de janeiro de 1890 , por meio do Decreto $n^{\circ}$ 181, o Chefe do Governo Provisório da República dos Estados Unidos do Brasil instituiu o casamento civil para o Estado (BRASIL, 1890b). O capítulo I sobre as formalidades preliminares do casamento apontava que os pretendentes deviam habilitar-se perante o oficial do registro civil e apresentarem os seus documentos relacionados e, a seguir, o oficial redigia um ato resumido em forma de edital a fim de ser publicado duas vezes, com um intervalo de sete dias e fixado em lugar aparente (BRASIL, 1890b). No Capítulo II desse documento tratavam-se dos impedimentos do casamento, apontando que eram proibidos para se casarem "as mulheres menores de 14 anos e os homens menores de 16", assim como as pessoas casadas, o adúltero com o seu corréu, raptor com raptada, entre outros (BRASIL, 1890b). Vale ressaltar que desde 1890 permitia-se o casamento em lugar particular e, para tanto, deviam-se realizá-lo de portas abertas. Salienta-se que durante a celebração, tanto em casas de audiências, quanto em lugares particulares, deviam estar presentes a autoridade competente para presidir o casamento e o oficial do registro. No capítulo sobre a celebração ainda eram descritos como devia ser o procedimento quanto: ao consentimento por escrito, ao regime; a recusa de repetição da fórmula legal, o arrependimento ou que o casamento não seja por espontânea vontade; a pessoas enfermas; falta ou impedimento de autoridade competente e do oficial do registro para a realização do ato; iminente risco de vida do contraente; casamento de estrangeiro com brasileira; e contraentes parentes acima de $3^{\circ}$ grau (BRASIL, 1890b). O Capítulo VII apresentava os efeitos do casamento neste âmbito civil. Também vale ressaltar que, naquela ocasião, não se tinham os direitos e deveres igualitários entre homens e mulheres.

Neste Decreto $\mathrm{n}^{\circ} 181$, de 1890 , também se apresentavam as possibilidades de anulação do casamento e do divórcio. Essa legislação apontou que o pedido para o divórcio deveria estar baseado em quatro motivos, a saber:

$$
\begin{aligned}
& \S 1^{\circ} \text { Adulterio. } \\
& \S 2^{\circ} \text { Sevicia, ou injuria grave. } \\
& \S 3^{\circ} \text { Abandono voluntario do } \\
& \text { domicilio conjugal e prolongado por } \\
& \text { dous annos continuos. }
\end{aligned}
$$


$\S 4^{\circ}$ Mutuo consentimento dos conjuges, si forem casados ha mais de dous annos. (BRASIL, 1890b).

Em 1916 foi publicado o primeiro Código Civil Brasileiro, inspirado no modelo alemão de 1896 Bürgerliches Gesetzbuch (BGB) - em vigor desde 1900. Esse código possuía também alguns pontos de afinidade com o Código Civil Francês de 1804, "como, ad exemplum, no que se refere à aplicação temporal da norma, pois ficou preservada a regra consagrada no Código Napoleão segundo a qual a lei dispõe para o futuro, não podendo retroagir." (STOCO, 2004, p. 8). Outra afinidade referia-se à adoção do regime de comunhão universal, de forma legal, “Art. 262. O regime da comunhão universal importa a comunicação de todos os bens presentes e futuros dos cônjuges e suas dívidas passivas, com as excepções dos artigos seguinte. [...]” (BRASIL, 1916), que vigorou até a Lei do Divórcio (STOCO, 2004).

No Código Civil Brasileiro, sancionado por meio da Lei $n^{\circ} 3.071$, de $1^{\circ}$ de janeiro de 1916, passou-se a regular os direitos e obrigações de ordem privada concernentes às pessoas, aos bens e às suas relações, e determinou-se a capacidade civil, os direitos de família, as relações pessoais dos cônjuges e o regime dos bens no casamento (BRASIL, 1916).
Nomeadamente sobre casamento, o Código Civil de 1916, na parte especial do Livro I Do direito de família, no Título I Do Casamento trouxe muito do que foi instituído pelo Decreto $\mathrm{n}^{\circ}$ 181. Nesse código, uma das mudanças foi a proibição da idade, que passava para "mulheres menores de dezesseis anos e os homens menores de dezoito.” (BRASIL, 1916). O Capítulo "Dos efeitos do casamento" do decreto foi tratado no código em Título II, em específico, "Dos efeitos jurídicos do casamento” (BRASIL, 1916). O Capítulo “Das formalidades preliminares” ratificou no código a realização pelo oficial: "Art. 180. A habilitação para casamento faz-se perante o oficial do registro civil $[\ldots]$ ” (BRASIL, 1916). No texto do código foram feitas muitas alterações na forma da redação e no sentido de atualização da língua e de deixarem mais claras e detalhadas algumas questões. Em geral, as abordagens são semelhantes, mas há pequenas modificações como: o prazo da publicação prévia da ata do casamento dos nubentes - antes eram duas vezes, com intervalo de sete dias (para publicação, a fixação era da primeira publicação até o quinto dia depois da segunda) e passa a quinze dias (tanto para publicação quanto a fixação aparente); e o prazo de validade da habilitação, anteriormente podendo-se casar no período de até dois meses, 
passando-se a três meses no novo código. Nos aspectos da celebração, foram suprimidos: a fórmula relatada anteriormente na qual os noivos a repetiam a fim de aceitar como marido e mulher, embora estivesse explícito que seriam declaradas as vontades dos nubentes, e o modelo do texto por extenso. Ainda nesse código de 1916, o divórcio passou a ser renomeado e tratado no Título IV como "Da dissolução da sociedade conjugal e da proteção dos filhos", no qual se tinha uma similaridade em vários aspectos apresentados anteriormente pelo decreto, mas com uma redação diferente, como a forma de dissolução do casamento que se finda pela morte, nulidade ou anulação e acrescentou-se a permissão ao desquite nos seguintes motivos: "I. Adultério. II. Tentativa de morte. III. Sevicia, ou injuria grave. IV. Abandono voluntário do lar conjugal, durante dois anos contínuos" (BRASIL, 1916).

A Constituição Federal de 1937, promulgada no Governo de Getúlio Vargas, teve um único artigo que fazia menção ao casamento, artigo 124, o qual apontava que: "A família, constituída pelo casamento indissolúvel, está sob a proteção especial do Estado. [...]” (BRASIL, 1937). Na Constituição Federal de 1946 instituiu-se que o casamento religioso também teria efeito civil, desde que fossem realizados conforme prescrito em lei. Já a Lei $n^{\circ} 1.110$, de 23 de maio de 1950, regulou o reconhecimento dos efeitos civis ao casamento religioso e estabeleceu como itens a habilitação prévia, a habilitação posterior e as disposições finais, os quais especificavam os procedimentos para este ato. Apresentou-se os artigos $2^{\circ}$ e $3^{\circ}$ que se referiam à habilitação prévia. (BRASIL, 1950).

Na Constituição Federal de 1988 criou-se a justiça de paz, na qual o casamento fica sob a sua competência. Também foi abordado de forma subliminar sobre o casamento no capítulo VII, que trata sobre a família. (BRASIL, 1988). Em 1996, a união estável foi regulada pela Lei $n^{\circ}$ 9.278, que reconheceu como entidade familiar, em seu artigo $1^{\circ}$, “a convivência duradoura, pública e contínua, de um homem e uma mulher, estabelecida com objetivo de constituição de família.” (BRASIL, 1996). Essa lei regula os direitos e deveres dos conviventes, os bens móveis e imóveis, a dissolução, e a conversão desta união em casamento a qualquer tempo. (BRASIL, 1996).

Aos 10 de janeiro de 2002, a Lei $n^{\circ} 10.406$ instituiu o Código Civil, que manteve a mesma estrutura germânica 
adotada anteriormente (STOCO, 2004). Incluiu-se no capítulo I Das disposições gerais, artigo 1.511, que "o casamento estabelece comunhão plena de vida, com base na igualdade de direitos e deveres dos cônjuges" (BRASIL, 2002). No mesmo capítulo foram dados nova redação e detalhamento no que tange aos casamentos religiosos, o que no código de 1916 também não havia, porém fora regulado pela Lei $\mathrm{n}^{\circ} 1.110$ em 1950, com exceção do que se refere de maneira explícita o terceiro parágrafo do artigo 1.516:

§ 3o Será nulo o registro civil do casamento religioso se, antes dele, qualquer dos consorciados houver contraído com outrem casamento civil. (BRASIL, 2002).

Uma das alterações neste código, em comparação ao de 1916, é em relação à idade para o casamento e aponta que podem se casar o homem e a mulher com dezesseis anos, entretanto exige-se a autorização de ambos os pais (BRASIL, 2002).

$\mathrm{O}$ casamento entre pessoas do mesmo sexo foi regulamentado por meio da Resolução $\mathrm{n}^{\circ} 175$, de 14 de maio de 2013, que em seu artigo $1^{\circ}$ resolve que é "vedada às autoridades competentes a recusa de habilitação, celebração de casamento civil ou de conversão de união estável em casamento entre pessoas de mesmo sexo." (BRASIL, 2013).

Em 16 de março de 2015 foi sancionado o novo Código de Processo Civil por meio da Lei $\mathrm{n}^{\circ} 13.105$, que trouxe alterações em relação ao regime de bens do casamento para o divórcio, a separação consensual e a extinção da união estável. Também apresenta inovações sobre o divórcio, a separação judicial e a conciliação e decreta em seu artigo 165: "Os tribunais criação centros judiciários de solução consensual de conflitos, responsáveis pela realização de sessões e audiências de conciliação e mediação e pelo desenvolvimento de programas destinados a auxiliar, orientar e estimular a autocomposição.” (BRASIL, 2015).

Assim, constata-se que o Brasil possui uma mudança gradual e frequente das suas leis pertinentes ao casamento, embora aqui tenham sido tratadas somente as principais legislações e suas atualizações que tiveram relevância na institucionalização do casamento e nos assuntos que o perpassam.

Os Direitos dos Homossexuais e a Legalização do Casamento 
Cidadãos e cidadãs homossexuais têm lutado pelos seus direitos em diferentes lugares do mundo. No Brasil estas se ampliaram após a redemocratização, com os debates pelo direito destas minorias e "ao combate e à criminalização da homofobia" como aponta Maia (2015, p. 201). Entretanto, ainda se tem os problemas de atentados homofóbicos, culminando em agressões de todas as formas, sem contar as facções religiosas que corroboram para aumentar esta violência.

Reações a isso, por outro lado, também são noticiadas, inclusive em países que primaram por ideais de democracia; ressalte-se aqui, por exemplo, a França e seus princípios de liberté, egalité et fraternité que parecem colocados em xeque por parcela retrógrada da sua sociedade avessa ao 'casamento gay', a qual ocupou as ruas de Paris, no ano de 2013, em duas grandes manifestações, uma aos 13 de janeiro (contando com cerca de 340.000 participantes) e outra no dia 24. de março (havendo aproximadamente $\quad 300.000$ integrantes)." (MAIA, 2015, p. 201).

Embora esse aumento da cultura homossexual seja crescente, ainda existem cerca de 80 países que proíbem a homossexualidade pela lei, que se inclui a pena de prisão ou de banimento e até a pena de morte (CATTAN; LEROY, 2013).

É fácil falar que as pessoas têm seus direitos garantidos pela Constituição da República Federativa do Brasil em vigor, promulgada em outubro de 1988 cujo art. 3, inciso IV, considera que constitui como objetivo fundamental da República Federativa do Brasil "promover o bem de todos, sem preconceitos de origem, raça, sexo, cor, idade e quaisquer outras formas de discriminação." (BRASIL, 2013a). Contudo, uma parcela da população, apesar de ter seus direitos garantidos, precisa lutar para usufrui-los na forma da lei e recorrer à justiça para $o$ seu cumprimento. Note-se ainda que na constituição brasileira existe um conflito de ideias sobre a composição da família; pois o art. 226, parágrafo $3^{\circ}$, estabelece "Para efeito da proteção do Estado, é reconhecida a união estável entre $\mathrm{o}$ homem e a mulher como entidade familiar, devendo a lei facilitar sua conversão em casamento." (BRASIL, 2013a). Um lado defende que isto diz respeito à união estável entre homem e mulher e não pode ser entendida como uma união entre duas pessoas do mesmo sexo. Entretanto, o segundo posicionamento respalda-se a partir do que garante a $\mathrm{CF}$, art. $3^{\circ}$ e os princípios da igualdade, da dignidade 
humana, da privacidade e do pluralismo, assim como o art. $5^{\circ}$, o qual consiste em que "a lei punirá qualquer discriminação atentatória dos direitos e liberdades fundamentais.” (BRASIL, 2013a). Isto acarretou interpretações pessoais, inclusive de juízes, até que houve o pronunciamento do Supremo Tribunal Federal acerca do assunto, já que o Legislativo brasileiro tem uma bancada religiosa e conservadora muito operante, que conseguiu assento na Comissão de Direitos Humanos, como observa Maia (2015).

Muitos processos jurídicos no Brasil ocorreriam movidos pela luta da efetivação destes princípios em diferentes aspectos, fossem eles para o benefício de saúde, pensão ou união civil. Alguns casais homossexuais conseguiram realizar uma união estável em alguns estados nos quais foram promulgados provimentos, circulares ou resolução normativa com o reconhecimento da união estável entre pessoas do mesmo sexo, ou por ações jurídicas nas quais os juízes deram parecer favorável à união estável. O fato é que até 14 de maio de 2013 os casais homossexuais precisavam recorrer à justiça para que fosse permitida a união estável. Nesta data foi aprovada, pelo Conselho Nacional de Justiça, a Resolução $\mathrm{N}^{\mathrm{o}}$ 175, a qual resolve: "É vedada às autoridades competentes a recusa de habilitação, celebração de casamento civil ou de conversão de união estável em casamento entre pessoas de mesmo sexo." (BRASIL, 2013b). A partir desta resolução foi permitido este ato civil aos homossexuais de forma legal, sem possibilidade de contestação ou interpretação da lei em instâncias inferiores ao Supremo Tribunal. Entretanto, ainda se reivindica uma lei que regulamente este ato e que não deixe brechas para interpretações de juízes nos tribunais.

L'évolution du mariage et celle des attitudes envers l'homosexualité, ainsi que les changements provoqués par l'épidémie de sida, ont rendu cette union légale plus attirante pour les lesbiennes et les gays, et ce, pas seulement pour symboliser leur engagement mutuel, mais aussi parce que c'est un contrat qui encadre les rapports sociaux et financiers entre les conjoints et la société dans son ensemble. (ALDRICH, 2006, p. 362).

O primeiro país a legalizar este direito foi a Holanda, em 2001. Posteriormente, alguns países têm respaldado tal consentimento com ou sem direito à adoção e à procriação medicamente assistida e, atualmente, são 
mais de vinte, entre eles: Bélgica (2003), Espanha (2005), Canadá (2005), África do Sul (2006), Noruega (2009), Suécia (2009), Portugal (2010), Islândia (2010), Argentina (2010), Uruguai (2013), Nova Zelândia (2013), França (2013), Brasil (2013), Inglaterra e Escócia, estados dos Estados Unidos, como: Massachussets (2004), Connecticut (2008), Iowa (2009), Vermont (2009), Nova Iorque (2011), Washington (2012), Maryland (2012), Maine (2012) e Havaí (2013) (PATROCÍNIO, 2013).

Porém, ressalta-se que, em 1989, a Dinamarca liberou a "parceria registrada" de forma que esta união era reconhecida legalmente por meio da lei $n^{\circ} 372$ de 7 de junho; depois, sob o mesmo modelo dinamarquês, a Noruega aprovou a lei $n^{\circ} 40$ de 30 de abril de 1993; e outro país escandinavo, a Suécia, aprovou a lei 1994:1117 de 23 de junho de 1994, que também teve a mesma aplicação da Dinamarca de "parceria registrada", mas que entrou em vigor em $1^{\circ}$ de janeiro de 1995 (DIGOIX, 2008). Ainda, em 1993, na Noruega os gays podiam optar pela união civil, mas em 2009 que foi promulgada a lei liberando casamento, adoção e fertilização assistida a todos. (PATROCÍNIO, 2014). Os últimos países, respectivamente, a aderirem a esta legalização foram a Finlândia, em novembro de 2014, e a Irlanda, em maio de 2015.

A geografia dessas uniões entre homossexuais apontam que os casais se concentram mais nas grandes cidades, como Nova Iorque e São Francisco, nos Estados Unidos; Barcelona e Madrid, na Espanha; e Amsterdã, na Holanda (CATTAN; LEROY, 2013). Embora o 'pacto civil solidário’ (pacs) na França possa ser realizado entre pessoas do mesmo sexo, o crescimento do pacs na França é entre casais heterossexuais, com $95 \%$, contra $5 \%$ entre pessoas do mesmo sexo, em 2010 (CATTAN; LEROY, 2013). Entretanto, Cattan e Leroy (2013, p. 39) também avaliam que

[...] Ce n'est pas le moindre des paradoxes de cette innovation sociale, immédiatement considérée par ses partisans comme ses opposants comme un mariage homosexuel déguisé, et violemment combattue pour cela, que d'être devenue une forme d'union banalisée chez les hétérosexuels. [...].

A legitimação desta união entre homossexuais, na maioria dos países, é palco de discussões entre a população, políticos, magistrados e religiosos. Pesquisas são realizadas para saber a opinião pública sobre a questão. Na Escócia, o governo fez uma consulta pública obtendo 76,8 mil respostas, muitas de organizações religiosas e ONGs, 
de setembro a dezembro de 2011, na qual $67 \%$ foram contra o casamento gay e $32 \%$ a favor; e na Inglaterra, no primeiro semestre de 2012, 53\% se manifestaram a favor (PINHEIRO, 2013).

Em Iowa, nos Estados Unidos, uma pesquisa nacional divulgada em 2014, $45 \%$ aprovam o casamento gay e $46 \%$ preferem pela proibição. Entretanto, como para o amor existir independe de cor, raça, sexo, nem idade, duas mulheres aos 90 e 91 anos, após mais de sete décadas de relacionamento se casaram em uma cerimônia religiosa na Igreja Cristã, celebrado pela Reverenda Linda Hunsaker, em 06 de setembro de 2014, em Davenport, Iowa. (CLEMENTE, 2014).

No Brasil, conforme uma pesquisa encomendada ao Ibope, pela emissora de TV Globo e o jornal O Estado de São Paulo, em setembro de 2014 (um ano e quatro meses após a Resolução $\mathrm{N}^{\circ} 175$ e um mês antes das eleições presidenciais), 53\% dos brasileiros foram contrários ao casamento gay e $40 \%$ favoráveis. O índice a favor é crescente entre os que possuem curso superior, $55 \%$, e os jovens de 16 a 24 anos, 51\%. A maior rejeição é apresentada pelos homens, 58\%. Entre as mulheres 49\% são desfavoráveis e $44 \%$ consentem. (IBOPE, 2014).

A legalidade promove uma migração de casais para lugares onde se permite o casamento homossexual, o que torna o assunto um objeto/tema demográfico e geográfico no mundo contemporâneo. Assim, no caso de noivos de nacionalidades diferentes e um dos países de origem de um dos noivos proíbe este ato, mas o outro não, eles se casam naquele país onde o casamento é legal, como aconteceu com o príncipe italiano Giulio e o brasileiro Henrique. O casamento civil do príncipe Giulio Durini di Monza e o Henrique Mollica foi realizado em setembro de 2014, na casa da família brasileira de Giulio, no Rio de Janeiro, Brasil, em uma cerimônia reservada a 14 pessoas. Vale lembrar que na Itália a lei ainda não permite este ato entre pessoas do mesmo sexo, porém, Henrique foi inscrito no Livro de Ouro da Nobreza Europeia e possui títulos da nobreza. (ANGEL, 2014).

Embora as cerimônias de casamento sejam tradicionalmente atos privados, no Brasil, como forma de manifestação política tem-se feito celebrações públicas durante algumas Paradas LGBT (Lésbicas, Gays, Bissexuais e Transgêneros), como foi o caso em São Paulo e Maringá (Paraná). Na última Parada do Orgulho LGBT de Copacabana, Rio de Janeiro, realizada em novembro de 2014, casais homoafetivos/femeafetivos se inscreveram para consolidarem a união estável na 
semana seguinte em evento específico e público, que ocorreu aos 23 de novembro de 2014, reunindo num ritual coletivo de 160 casais homoafetivos/femeafetivos, no Armazém Utopia, no Rio de Janeiro, por meio de uma parceria entre o Programa Estadual Rio sem Homofobia e o Tribunal de Justiça do Estado do Rio de Janeiro. Este casamento coletivo, segundo o presidente do Programa Cláudio Nascimento, foi o maior do mundo e as mulheres representaram dois terços dos casais (RIBAS, 2014). Entre os casais “64\% casaram diretamente no civil, 32\% converteram a união estável em casamento e $4 \%$ formalizaram a união estável” (RIBAS, 2014).

\section{Manifestações Contrárias ao Casamento Homossexual}

Algumas das pesquisas, como as citadas acima, apontam que a divisão de opiniões da população sobre a aceitação dos casamentos homossexuais é acirrada e, na Escócia, o índice de rejeição ainda é muito alto, mesmo após a legalização da união estável entre pessoas do mesmo sexo. Essa diferença de pensamento é demonstrada através das manifestações a favor e contrárias ao homossexualismo que ocorrem em alguns lugares no mundo.
Si le monde gay est devenu plus homogène, sous l'action de la mondialisation, il s'est aussi fragmenté davantage. Dans certains pays, les objectifs communs du passé, principalement la lutte pour mettre fin à la discrimination légale, on été atteints et aucun autre but fédérateur n'est apparu. Au contraire même, certains journalistes ont défini de nouveaux objectifs qui contrarient les désirs d'un grand nombre d'homosexuels: pas de travestissement, pas de sexe avec mineurs, pas d'exhibition sado-maso, pas de drague dans les lieux publics, pas de promiscuité. (ALDRICH, 2006, p. 360).

$\mathrm{Na}$ França existe um grupo chamado "La Manif Pour Tous", nome advindo da lei "Mariage pour tous", que faz manifestações em oposição ao casamento e a adoção 'por todos' e suas consequências. No site de divulgação do movimento é possível encontrar a sua carta de ação na qual afirma ser um movimento pacífico et "Il s'oppose avec détermination aux projets contraires à l'humanité homme/femme et anti-famille du gouvernement", porém, deixa claro que "Il condamne fermement l'homophobie." (LA MANIF POUR TOUS, 2014). Essas manifestações fazem com que os governos temam aprovar leis que concedam outros 
direitos aos homossexuais, deixando em 'banho-maria' as discussões em relação à maternidade e à paternidade, como foi aconteceu na França, a fim de acalmar os protestos. Nos Estados Unidos, Barack Obama foi o primeiro presidente a declarar abertamente o seu apoio ao casamento de gays e lésbicas na campanha em 2012. Em 2013, Hillary Clinton, uma possível candidata às eleições norteamericanas em 2016, e Bill Clinton, expresidente, também anunciaram ser favoráveis ao casamento homossexual. No Brasil, há uma bancada política, com raízes religiosas, contra as solicitações de direitos dos gays e lésbicas. Esta bancada, composta por evangélicos e católicos conservadores, também tenta fazer com que os direitos adquiridos pelos homossexuais quanto à união estável, reconhecida pelo Supremo Tribunal Federal por meio da Resolução $\mathrm{N}^{\circ} 175$, sejam anulados. Em 2011 , o deputado João Campos protocolou um Projeto de Decreto Legislativo que ficou conhecido como "Projeto da cura gay", que estabelece normas para atuação dos psicólogos em relação à orientação sexual, de tratamentos que revertem a homossexualidade. Houve uma grande repercussão em torno desta proposta e ativistas protestaram e ressaltando que a orientação sexual não é doença, portanto não há o que se tratar ou curar.

Em Curitiba, Brasil, a prefeitura municipal da cidade ao noticiar sobre o casamento coletivo foi alvo de críticas por vereadores, os quais apresentaram uma moção de repúdio deste ato. Isso ocorreu em virtude do anúncio reforçando que este evento beneficiaria centenas de famílias, no qual os casais homossexuais também poderiam participar. (CHAGAS, 2014).

As causas dos homossexuais têm ganhado espaço também nos discursos políticos durante as campanhas eleitorais. Nas últimas eleições brasileiras, em outubro de 2014, o assunto foi palco de discussão, quando uma das candidatas à presidência, Marina Silva, colocou em seu plano de governo o apoio aos homossexuais, mas devido a algumas críticas no dia seguinte faz alterações e retirou tal menção (BRAGA, 2014). O candidato Aécio Neves tratou sobre o tema, mas não apresentou medidas práticas. A atual presidente do país, então candidata à reeleição, sequer citou em seu programa de governo e nas campanhas eleitorais qualquer intenção sobre o assunto. Este fato, aliado à nova bancada eleita de senadores, considerada como conservadora, faz com que algumas pessoas presumam de que este governo será mais difícil de reivindicar por direitos 
aos homossexuais ou que, ao menos, terão um pouco mais de empecilhos.

Se no plano da legalização civil o assunto é controverso, no plano religioso isto não é diferente, pois a maioria das igrejas são contra os casamentos gays. No cristianismo, igrejas católicas e protestantes alegam que na bíblia o casamento é definido com vistas à procriação entre homem e mulher, sendo assim, as pessoas do mesmo sexo não poderiam procriar naturalmente, além das menções que existem à ideia do pecado e de condenação da homossexualidade. Algumas igrejas evangélicas organizam manifestações contra o casamento gay e a adoção de crianças por casais homossexuais. Elas pregam que a relação entre gays é pecado, diante do que interpretam o texto do Levítico 18:22: "Não te deitarás com um homem, como se fosse uma mulher: isso é uma abominação". Há alguns pastores que ainda dizem que para afastar este 'mal' deveria logo encontrar uma mulher para não cair em tentação. Para este grupo a evolução sexual, a qual Aldrich se refere abaixo, parece não ter acontecido e que ainda vivem antes desse desenvolvimento:

avant la évolution sexuelle, on conseillait souvent aux homosexuels de se marier pour les aider à étouffer leur désirs inavouables, mais lorsque les psychiatres eurent découvert qu'il était impossible de changer l'orientation sexuelle, on le leur déconseilla, puisque cela n'aurait eu comme résultat que de les rendre malheureux, eux, leur femme et leur enfants. (ALDRICH, 2006, p. 362).

Concorda-se com as palavras de Mott (2006, p. 517) que mostram que é uma questão de tempo para que estas ideias religiosas contra o casamento homossexual não tenham mais a supervalorização que ainda é dada por algumas pessoas, que diz:

o argumento de que defender o casamento gay provocaria grande indignação da Igreja Católica não deve ser supervalorizado, pois Pio IX ameaçou excomungar todos os que apoiassem o casamento civil, e a Igreja perdeu essa batalha! Como também não conseguiu barrar a aprovação e aceitação geral da Lei do Divórcio, o uso do preservativo e dos anticoncepcionais, e nos próximos anos tudo leva a crer que há de ter de aceitar a homossexualidade, o fim do celibato do clero e até o aborto, como teve de engolir, a contragosto, a abolição da escravatura e a igualdade de direito das mulheres. (MOTT, 2006, p. 517). 
Do outro lado, os gays e lésbicas não querem ser reprimidos, mas sim livres e felizes consigo próprios e suas famílias. Dessa forma, lutam por seus ideais e formam seus grupos; protestam por seus direitos; se colocam contra as igrejas evangélicas, que fazem um embate duramente aos homossexuais, tanto na esfera religiosa quanto política; e encontram religiões que os aceitam, acolhem e apoiam em suas opções.

Em certas igrejas cristãs, os casamentos entre pessoas do mesmo sexo são permitidos, como a Metropolitan Commutity Church, nos Estados Unidos; a United Church of Canadá, no Canadá; a Igreja para Todos, Igreja da Comunidade Metropolitana e a Comunidade Cristã Nova Esperança, no Brasil. Recentemente, a Igreja Protestante Unida da França adotou no dia 17 de maio de 2015 a possibilidade da benção religiosa aos casais homossexuais, onde somente a Igreja Missão Popular Evangélica, uma igreja muito menor do que a Igreja Protestante Unida, já autorizava este gesto litúrgico para os casais de mesmo sexo (LE MONDE, 2015). Com estas aceitações, alguns casais têm realizado o seu sonho de casar-se em uma igreja, com toda a tradição dos rituais. Mott (2006, p. $518)$ há quase dez anos disse: “[ ...] Para milhões de seres humanos, o casamento tradicional, agora modernizado pela legalização do divórcio, é uma fonte de grande felicidade, amor recíproco, segurança emocional e material. [...]”.

\section{Ritual do Casamento Homoafetivo/Femeafetivos e as Tradições Mantidas}

Os ritos de passagem fazem parte da vida cotidiana dos seres humanos. O nascimento, o batizado, o casamento e a morte são acontecimentos recorrentes ao longo da vida de cada um. Segundo Van Gennep (2011) o casamento é um rito de passagem que é considerado também como um rito de agregação.

O ritual é um sistema cultural de comunicação simbólica. Ele é constituído de seqüências ordenadas e padronizadas de palavras e atos, em geral expressos por múltiplos meios. Estas seqüências têm conteúdo e arranjos caracterizados por graus variados de formalidade (convencionalidade), estereotipia (rigidez), condensação (fusão) e redundância (repetição). A ação ritual nos seus traços constitutivos pode ser vista como "performativa" em três sentidos; 1) no sentido pelo qual dizer é também fazer alguma coisa como um ato convencional [como quando se diz “sim” à pergunta do padre em um 
casamento]; 2) no sentido pelo qual os participantes experimentam intensamente uma performance que utiliza vários meios de comunicação [um exemplo seria o nosso carnaval] e 3), finalmente, no sentido de valores sendo inferidos e criados pelos atores durante a performance [por exemplo, quando identificamos como "Brasil" o time de futebol campeão do mundo]. (PEIRANO, 2003, p. 09).

A cerimônia de casamento tem seu ritual e começa desde o dia em que as pessoas decidem se unir maritalmente. Com a conquista legalizada da união estável entre pessoas do mesmo sexo, os casamentos homossexuais tornaram-se mais difundidos, o que foi possível fazer a análise de alguns rituais e tradições que assimilados dos casamentos heterossexuais. O direito está para todos, assim como o sonho e desejos de ter uma cerimônia completa. Embora algumas religiões não permitam casamento homoafetivo/femeafetivo, a cerimônia acontece da mesma forma, desde o planejamento até o encerramento com a lua-de-mel, com o mesmo ritual, tendo a designação de testemunhas, o consentimento mútuo, a troca das alianças, o beijo e, além disso, os(as) declaram casados(as).
Neste estudo foram pesquisados os casamentos de lésbicas/ gays, famosos/ anônimos, e analisadas as fotografias e as informações obtidas em sites e blogs, a fim de verificar como estes rituais se respaldam nas cerimônias de casamentos heterossexuais, nos quais abrangem uma ritualidade semelhante, com pequenos detalhes distintos. A principal diferença entre os rituais do casamento homo e heterosexuais são nos momentos das entradas dos/das noivos/noivas, quando alguns casais optam em entrar juntos no momento da cerimônia. Outro detalhe diferente é em relação ao traje, no qual ambos usam ternos/meio fraque/ fraque ou vestidos, mas nota-se que mesmo sendo o mesmo estilo utilizado, a tradição se mantém em uma boa parte das comemorações, com o vestido branco e o terno preto, cinza ou branco.

O posicionamento das "personagens" do casamento durante o ritual se mantém da mesma forma como é feito nas cerimônias heterossexuais. Os(as) noivos(as) no centro e à frente, assim como o(a) celebrante, porém este voltado para o público; quando os pais participam ficam próximos dos(as) noivos(as), ao lado e à frente; os padrinhos nas laterais frontais ou na primeira fileira; e os convidados fazem parte da "plateia”. Este posicionamento pode ser um pouco 
diferente em qualquer cerimônia em virtude do tamanho do espaço e da quantidade de pessoas, o que geralmente é sugerido pelos profissionais cerimonialistas.

Estes rituais fazem elucubrar quando os homossexuais reivindicam pelos direitos civis e questionam as normatividades, rompendo com o modelo tradicional de família. Porém, conforme foi visto acima, nos rituais acabam assimilando essas normatividades e se enquadrando nos mesmos padrões ritualísticos dos heterossexuais. é interessante refletir que mesmo com o embate em questões dos direitos civis, depois de conquistadas tais reivindicações, no momento em que vão celebrar o ritual, começam buscando por aquilo que é aceito pela sociedade, ou melhor, o que é 'imposto’ pela sociedade: um ritual tradicional com cortejos, madrinhas e padrinhos, damas e pajens, trajes típicos para a cerimônia, aliança, beijo, bolo e brinde. Porque fazem e o que esperam com isso?

Thomson (2010) aponta existir cinco elementos que compõem a natureza humana para o desenvolvimento dos códigos morais. Dentre eles reflete-se que o desejo de aprovação seja um componente que possa explicar este desejo da realização do tradicional ritual de casamento. Para o autor, "a sensação de obter a aprovação dos pares transforma-se num hábito de aprovação pessoal ou de censura, o qual se designa, latu sensu, por consciência." (THOMSON, 2010, p. 27). O fato é que este modelo existente é tão forte na sociedade ocidental que marca efetivamente esta passagem. Este ritual celebra um momento feliz, a união de uma família; soleniza a igualdade, a conquista de seus direitos obtidos através de muita luta. Embora se critique a normatividade aderem ao ritual como forma de realização de um sonho, de casar-se em uma cerimônia tradicional aceita pela sociedade.

O ritual é marcado por tradições e elas também estão inseridas nos casamentos homossexuais, como foi visto acima. Em geral, nesses casamentos também há alguns símbolos que fazem parte de uma cerimônia, como o buquê (quando mulheres), as alianças, o vestido branco e/ou o terno/fraque/meio fraque (preto, cinza ou branco), o brinde, o bolo e o beijo. Hobsbawm (2002), na obra "A invenção das tradições", traz uma discussão acerca do tema e aponta que as tradições podem ser tanto aquelas que surgiram recentemente ou em um tempo indeterminado, que não se sabe ao certo quando apareceram, quanto às que foram 
inventadas. $\mathrm{O}$ autor entende por "tradição inventada"

[...] um conjunto de práticas, normalmente reguladas por regras tácitas ou abertamente aceitas: tais práticas, de natureza ritual ou simbólica, visam inculcar certos valores e normas de comportamento através da repetição, o que implica, automaticamente, uma continuidade em relação ao passado. Aliás, sempre que possível, tenta estabelecer continuidade com um passado histórico apropriado. [...] Contudo, na medida em que há referência a um passado histórico, as tradições "inventadas" caracterizam-se por estabelecer com ele uma continuidade bastante artificial. (HOBSBAWM, 2002, p. 9).

Percebe-se que ao tempo em que estes casais homossexuais questionam a normatividade em relação às regras de conduta e do conceito de família, buscam estes rituais tradicionais aos quais são repletos de normas de comportamento e valores, conforme pode ser interpretado no conceito acima. Hobsbawm (2002) ainda aponta que a tradição advém na tentativa de deixar os acontecimentos imutáveis e invariáveis de encontro com as inovações e mudanças do mundo moderno, no aspecto da vida social. Sendo assim, apresentam-se nestes casamentos homossexuais, alguns destes contrastes do moderno com o "antigo", da mesma forma como é realizado nos moldes dos casamentos heterossexuais.

\section{Considerações Finais}

A busca pelos direitos igualitários não é recente e ainda continua pelos homossexuais para que tenham seus direitos equitativos tais como aos heterossexuais, conforme previsto em lei ao se abordar a igualdade entre as pessoas, sem que haja distinção por raça, credo ou sexo, tanto no Brasil e outros países ocidentais. Assim como, por outro lado, existem algumas igrejas e grupos opositores procurando coibir, negar e retalhar que estas conquistas sejam alcançadas.

Os homossexuais conseguiram também que o ritual do casamento possa ser oficializado, com todas as simbologias e tradições que trazem dos heterossexuais a fim de concretizarem a realização de um sonho. Entretanto, o que eles ainda buscam é por um reconhecimento de uma parcela da população que este ato civil e religioso é para todos, sem diferença pelas escolhas sexuais. Eles não querem ir contra as normas, mas sim serem aceitos dentro delas. 
NOTAS

1 Possui graduação em Turismo pela Universidade Católica Dom Bosco (1999), mestrado em Turismo: Planejamento e Gestão Ambiental e Cultural pelo Centro Universitário Ibero Americano (2002) e Doutorado em Geografia pela Universidade Federal de Goiás (2016).

2 Possui graduação em Bacharelado em Geografia pela Universidade do Estado do Rio de Janeiro (1987), graduação em Licenciatura em Geografia pela Universidade do Estado do Rio de Janeiro (1988), mestrado em Geografia pela Universidade Federal do Rio de Janeiro (1994) e doutorado em Geografia pela Universidade Federal do Rio de Janeiro (2002). Atualmente é professor associado no DEGEO/UFJF, pesquisador do NuGea e atua como colaborador no Programa de PósGraduação em Geografia do IESA/UFG. Tem experiência na área de Geografia, com ênfase em Geografia Cultural, atuando principalmente nos seguintes temas: tradições, rituais e festas populares. Bolsista CAPES de Pós doutorado no ENEC/Sorbonne/Paris IV (2015).

${ }^{3}$ Em Portugal o padroado era uma tradição bem antiga, nascida nos tempos da reconquista: no dia 15 de março de 1319, a "Ordem de Cristo" é formada com antigos fundos da riquíssima Ordem dos Templários. Como Portugal era terra essencialmente "reconquistada" aos mouros, a Ordem de Cristo ganhou importância $e$ autoridade. Funcionava como órgão canalizador dos recursos do país para os cofres da nobreza territorial. Mas como Portugal, antes da aventura marítima, era terra de agricultura, a importância financeira e política da ordem era relativamente modesta.

Tudo isso mudou com a conquista de Ceuta, em 1415. Sendo esta empresa marítima, como todas as empresas marítimas, essencialmente comercial e burguesa, a Ordem de Cristo começou a proclamar bem alto seus direitos sobre os recursos trazidos a Portugal por esta nova experiência, proferindo discursos de teor religioso e evangélico, $e$ protestando sua vontade missionária diante das novas descobertas $[\ldots]$

[...] Do ano 1442 em diante, direito de padroado significa direito de conquista: eis o sentido das bulas pontifícias. Portugal é o senhor dos mares “nunca

dantes navegados", organizador da Igreja em termos de conquista e redução, planificador da união entre missão e colonização.

Por onde chegam os portugueses eles plantam o famoso "padrão" que traz as armas reais e a cruz intrinsecamente ligadas entre si. Portugal goza dos favores da Cúria Romana em negócios de além-mar. (HOORNAERT, 1992, p. 34-5).

4. Este termo é utilizado para referir-se às situações anteriores, mas que não necessariamente tenha ocorrido há muitos anos.

\section{REFERÊNCIAS BIBLIOGRÁFICAS}

ALDRICH, Robert. Une histoire de l'homosexualité. Paris: Seuil, 2006.

ANGEL, Hildegard. No Rio de Janeiro, um casamento belo, único e exemplar, de um brasileiro que passa a deter os títulos de nobreza de seu marido 
europeu. Hildegard Angel, 04 set. 2014. Disponível em:

$<$ http://www.hildegardangel.com.br/?p=41392>. Acesso em: 07 out. 2014.

BRAGA, Isabel. PSB retira do programa de governo apoio a aprovação do projeto do casamento civil gay. $\mathrm{O}$ Globo, 30 ago. 2014. Disponível em: $<$ http://oglobo.globo.com/brasil/psb-retira-doprograma-de-governo-apoio-aprovacao-doprojeto-do-casamento-civil-gay-13782398>. Acessado em: 04 mai. 2015.

BRASIL. Lei $n^{\circ}$ 10.406, de 10 de janeiro de 2002. Institui o Código Civil. Disponível em: <http://www.planalto.gov.br/ccivil_03/leis/2002 /110406.htm>. Acesso em: 25 jan. 2015.

BRASIL. Constituição (1988). Constituição da República Federativa do Brasil. Brasília, DF: Senado, 1988.

BRASIL. Constituição dos Estados Unidos do Brasil de 1937. Disponível em: <http://www.planalto.gov.br/ccivil_03/constituic ao/constituicao37.htm>. Acesso em: 19 mar. 2015.

BRASIL. Decreto $n^{\circ}$ 10.044, de 22 de setembro de 1888. Fixa o dia em que deve começar a ter execução, em todo o Imperio, o Regulamento do Registro Civil dos nascimentos, casamentos e obitos. Disponível em: <http://www2.camara.leg.br/legin/fed/decret/ 18 24-1899/decreto-10044-22-setembro-1888542833-publicacaooriginal-52347-pe.html>. Acesso em: 22 de jan. 2015.

BRASIL. Decreto $n^{\circ}$ 119- $A$, de 7 de janeiro de 1890a. Prohibe a intervenção da autoridade federal e dos Estados federados em materia religiosa, consagra a plena liberdade de cultos, extingue o padroado e estabelece outras providencias. Disponível em: <http://www.planalto.gov.br/ccivil_03/decreto/1 851-1899/d119-a.htm>. Acesso em: 22 jan. 2015

BRASIL. Decreto $n^{\circ} 181$, de 24 de jan. 18906. Promulga a lei sobre o casamento civil. Disponível em:

<http://www.planalto.gov.br/ccivil_03/decreto/1 851-1899/D181.htm>. Acesso em: 22 jan. 2015.

BRASIL. Decreto $n^{0}$ 5.604, de 25 de março de 1874. Manda observar o Regulamento desta data para execução do art. $2^{\circ}$ da Lei $n^{\circ} 1829$ de 9 de Setembro de 1870 , na parte em que estabelece o registro civil dos nascimentos, casamentos e obitos. Disponível em: <http://www2.camara.leg.br/legin/fed/decret/ 18 24-1899/decreto-5604-25-marco-1874-5502 11- publicacaooriginal-65873-pe.html>. Acesso em: 03 mar. 2015.

BRASIL. Lei $n^{\circ} 1.110$, de 23 de maio de 1950. Regula o reconhecimento dos efeitos civis ao casamento religioso. Disponível em: <http://www.planalto.gov.br/ccivil_03/Leis/195 o-1969/L11 10.htm>. Acesso em: 4 fev. 2015.

BRASIL. Lei $n^{\circ}$ 1.829, de 9 de setembro de 1870. Sancciona o Decreto da Assembléa Geral que manda proceder ao recenseamento da população do Imperio. Disponível em: $<$ http://legis.senado.gov.br/legislacao/ListaPubli cacoes action? $\mathrm{id}=74497 \&$ tipoDocumento $=$ LEI $\&$ tip oTexto $=$ PUB $>$. Acesso em: 22 de jan. 2015.

BRASIL. Lei $n^{\circ}$ 13.105, de 16 de março de 2015. Código de Processo Civil. Disponível em: <http://www.planalto.gov.br/ccivil_03/_Ato2015 -2018/2015/Lei/L13105.htm>. Acesso em: 24 mar. 2015 .

BRASIL. Lei $n^{\circ}$ 3.071, de 1 de janeiro de 1916. Código Civil dos Estados Unidos do Brasil. Disponível em: <http://www.planalto.gov.br/ccivil_03/leis/1307 1.htm>. Acesso em: 2 de fev. 2015.

BRASIL. Lei $n^{\circ}$ 6.015, de 31 de dezembro de 1973. Dispõe sobre os registros públicos, e dá outras providências. Disponível em: <http://www.planalto.gov.br/ccivil_03/leis/L601 5original.htm>. Acesso em 12 out. 2014.

BRASIL. Lei $n^{\circ}$ 9.278, de 10 de maio de 1996. Regula o $\S 3^{\circ}$ do art. 226 da Constituição Federal. Disponível em: $<$ http://www.planalto.gov.br/ccivil_03/leis/1927 8.htm>. Acesso em: 4 fev. 2015.

BRASIL. Lei $n^{\circ} 6.216$, de 30 de junho de 1975 . Altera a Lei $n^{\circ}$ 6.015, de 31 de dezembro de 1973, que dispõe sobre os registros públicos. Disponível em:

<http://www.planalto.gov.br/ccivil_03/leis/L62 1 6.htm>. Acesso em 12 out. 2014.

BRASIL. Conselho Nacional de Justiça. Resolução $n^{o} 175$, de 14 de maio de 2013. Dispõe sobre a habilitação, celebração de casamento civil, ou de conversão de união estável em casamento, entre pessoas do mesmo sexo. Disponível em: <http://www.cnj.jus.br/images/resol_gp_175_20 13.pdf $>$. Acesso em: 4 fev. 2015.

CATTAN, Nadine; LEROY, Stéphane. Atlas mondial des sexualités: libertés, plaisirs et interdits. Paris: Autrement, 2013. 96 p.

CHAGAS, Thiago. Bancada evangélica força prefeitura de Curitiba a retirar do ar anúncio de casamento gay em cerimônia coletiva. Gospel mais, 02 
out. 2014. Disponível em: <http://noticias.gospelmais.com.br/casamentogay-bancada-evangelica-prefeitura-anuncio71572.html>. Acesso em: 12 nov. 2014.

CLEMENTE, Isabel. A história de amor de Alice Dubes e Vivian Boyack. Época, 21 set. 2014. Disponível $\mathrm{em}:$ <http://epoca.globo.com/vida/noticia/2014/09/h istoria-de-amor-de-balice-dubes-e-vivianboyackb.html>. Acesso em: 04 nov. 2014.

CRISTIANI, Claudio Valentim. O direito no Brasil Colonial. In: WOLKMER, Carlos (Org.). Fundamentos de história de direito. 3. ed. Belo Horizonte: Del Rey, 2006. 400p.

DIGOIX, Marie. "Scandinave Le concept nordique d'égalité entre differénciation et universalisme". In: DIGOIX, Marie; FASSIN, Éric; RAULT, Wilfried. Mariages et homosexualités dans le monde: l'arrangelment des normes familiales. Paris: Autrement, 2008. 18-33.

HOBSBAWM, E. A invenção das tradições. Rio de Janeiro: Paz e Terra, 2002.

HOORNAERT, Eduardo, AZZI, Riolando, GRIJP, Klaus van der et al. História da Igreja no Brasil (primeira época). $4^{\mathrm{a}}$ ed. Petrópolis: Vozes, 1992. Tomo II/1, p. 154-244.

IBOPE. 83\% da população é a favor da redução da maioridade penal. Ibope, 17 set. 2014. Disponível em: $\quad<$ http://www.ibope.com.br/pt$\mathrm{br} /$ noticias/paginas/83-da-populacao-e-a-favorda-reducao-da-maioridade-penal.aspx $>$. Acesso em: 12 out. 2014.

LA MANIF POUR TOUS. Charte des actions la manif pour tous. Disponível em: <http://www.lamanifpourtous.fr/fr/qui-sommesnous/notre-charte-d-action $>$. Acesso em: 08 nov. 2014.

LE MONDE. L'Eglise protestante unie de France permet désormais de bénir les couples homosexuels. 17 mai. 2015. Disponível em: <http://www.lemonde.fr/religions/article/2015/ 05/17/l-eglise-protestante-unie-de-france-permetdesormais-de-benir-les-coupleshomosexuels_4634859_1653130.html>. Acesso em: 17 mai. 2015.

MAIA, Carlos Eduardo Santos. "Go West, in the open air: Parada do Orgulho LGBT Goianiense - da repressão à turistificação”. Revista Latinoamericana de Geografia e Gênero. Ponta Grossa, v. 6, n.1, jan./jul. 2015. p. 200-221.

MOTT, Luis. "Homo-afetividade e direitos humanos”. Estudos Feministas. Florianópolis, 14(2), mai-ago, 2006. p. 509-521.

PATROCÍNIO, Carol. 22 países já legalizaram a união gay. Yahoo Mulher, 25 abr. 2013. Disponível em:

<https://br.mulher.yahoo.com/blogs/preliminare s/22-pa\%C3\%ADses-j\%C3\%A 1-legalizaramuni\%C3\%A3o-gay-100932515.html>. Acesso em: o8 out. 2014.

PEIRANO, Mariza. Rituais ontem e hoje. Rio de Janeiro: Jorge Zahar, 2003. Disponível em: <file:///C:/Raquel/Doutorado/Doutorado\%20sa ndu\%C3\%ADche/Ritual/PEIRANO,\%20Mariza\% 20Rituais\%20ontem\%20e\%2ohoje.pdf $>$. Acesso em 13 fev. 2015.

PINHEIRO, Aline. Deputados britânicos aprovam casamento gay. Consultor Jurídico. 06 fev. 2013. Disponível em: <http://www.conjur.com.br/2013fev-06/casamento-gay-vence-primeira-batalhaparlamento-reino-unido $>$. Acesso em: 13 out. 2014.

RIBAS, Raphaela. Casamento coletivo festeja a união de 160 casais gays na cidade. O Globo, 23 nov. 2014. Disponível em: <http://oglobo.globo.com/rio/casamentocoletivo-festeja-uniao-de-160-casais-gays-nacidade-14639905 >. Acesso em: 24 nov. 2014.

STOCO, Rui. Responsabilidade civil no Código Civil Francês e no Código Civil Brasileiro. Palestra proferida no Seminário em Comemoração ao Bicentenário do Código Civil Francês, 27 de setembro de 2004. Disponível em: <http://www.egov.ufsc.br/portal/sites/default/fil es/anexos/9704-9703-1-PB.pdf $>$. Acesso em: 04 fev. 2015 .

THOMSON, Oliver. História do pecado. Lisboa: Guerra \& Paz, 2010.

VAN GENNEP, Arnold. Os ritos de passagem: estudo sistemático dos ritos da porta e da soleira, da hospitalidade, da adoção, gravidez e parto, nascimento, infância, puberdade, iniciação, coroação, noivado, casamento, funerais, estações, etc. Petrópolis: Vozes, 2011. 184p. 
HOMOSEXUAL MARRIAGE: LEGALIZATION AND RITUAL

ABSTRACT: AN OVERVIEW OF THE MARRIAGE LEGALIZATION BETWEEN HOMOSEXUALS IN BRAZIL AS WELL AS IN THE WORLD HAS BEEN DONE IN THIS PAPER. SOME OPPOSITE ACTIVITY GROUPS HAS ALSO BEEN PRESENTED, AND IT WAS AIMED TO COMPARE HOMOSEXUAL MARRIAGES WITH HETEROSEXUAL MARRIAGES IN WHAT CONCERNS BOTH RITUAL AND TRADITIONS. AN EXPLORATORY STUDY HAS BEEN DEVELOPED, WHICH WAS BASED ON BOTH LITERATURE AND DOCUMENTS ABOUT RITUAL, TRADITION AND STABLE UNION LEGISLATION.

KEY-WORDS: HOMOSEXUAL MARRIAGE; STABLE UNION LEGISLATION; RITUAL; TRADITION

\section{MARIAGE HOMOSEXUELLE: LÉGALISATION ET RITUEL}

RÉSUMÉ: CE TRAVAIL VISE FOURNIR UN RESUME DE LA FAÇON DONT IL A ETE L'INSTITUTIONNALISATION DU MARIAGE Et DE LA LEGALISATION DU MARIAGE DES HOMOSEXUELS AU BRESIL ET DANS LE MONDE ; ET AUSSI LES MOUVEMENTS EN OPPOSITION A CETTE DEMANDE. IL VISE EGALEMENT A ANALYSER LA FAÇON DONT LES MARIAGES HOMOSEXUELS ILS NOUS SOUTIENNENT LES MARIAGES heteroseXUELS EN CE QUI CONCERNE LE RITUEL. COMME DEMARCHE METHODOLOGIQUE EST UNE ETUDE EXPLORATOIRE A TRAVERS DES RECHERCHES DOCUMENTAIRES ET BIBLIOGRAPHIQUES SUR LES THEMES RITUELS ET TRADITION, L'INSTITUTIONNALISATION DE MARIAGE ET EN PARTICULIER LA LEGISLATION RELATIVE A LE PACTE CIVIL DE SOLIDARITE (PACS).

MOTS-CLÉS: MARIAGE HOMOSEXUEL, LEGALISATION DU PACS, RITUEL, TRADITION. 